\title{
UNA FUENTE PARA EL ESTUDIO DE LA GEOGRAFÍA ECLESIÁSTICA DE GALICIA EN LA BAJA EDAD MEDIA: LAS TASACIONES DEL SUBSIDIO Y LA DÉCIMA
}

\author{
Por \\ MERCEDES VÁZQUEZ BERTOMEU ${ }^{1}$
}

\section{RESUMEN}

La tasa más importante que pesa sobre el clero gallego es la décima, entregada inicialmente en beneficio del pontificado y más tarde al tesoro real, dando lugar al canon que en el siglo XV se conoce como «décima y subsidio del clero». El pago que el representante diocesano hace al recaudador pontificio o real es el punto final de un proceso cuyos pormenores son aquí descritos para el caso de las diócesis gallegas.Este gravamen, que afecta a todo los beneficios diocesanos, dio lugar al nacimiento de un tipo documental específico conocido como tasación en el que se establece la cantidad que cada contribuyente debe aportar y que es de gran interés para el acercamiento a la geografía diocesana bajomedieval.

\footnotetext{
${ }^{1}$ Investigación realizada dentro del proyecto de investigación Diccionario Biográfico de la Galicia de los Trastámara (1369-1480) realizado en el Instituto de Estudios Gallegos «Padre Sarmiento» (CSIC) y financiado por la Fundación Pedro Barrié de la Maza.
}

«CUADERNOS DE ESTUDIOS GALLEGOS», Tomo XLIX, Fascículo 115, Santiago 2002. 


\title{
PALABRAS CLAVE
}

Variantes paleográficas, gallego, multilingüismo.

\begin{abstract}
The most important tax that Galician clergy must confront in late Middle Ages is the decima, delivered initially to the Pontificate and afterwards to the royal chambre, which became the revenue called in the century XV «decima y subsidio del clero». The payment that the diocesan representative does to the papal or royal collector is the final point of a process whose details are described here for the case of the Galician churches. This charge, which envolves all the diocesan benefices, caused a specific documentary type known as taxatio in which is established a roll of contributors and a valuation of beneficies - a very useful source to know late medieval dioceses.
\end{abstract}

\section{KEYWORDS}

Paleographical variants, Galician language, Multilinguism.

Nuestro conocimiento sobre las sedes eclesiásticas de Galicia durante el período medieval sigue siendo, a pesar de los esfuerzos desarrollados en los últimos años ${ }^{2}$, bastante impreciso sobre todo cuando nos alejamos de la ciudad episcopal y de las entidades en ella establecidas. No sabemos a ciencia cierta -ni de un modo aproximado-, los beneficios (parroquiales

${ }^{2}$ Un ejemplo de ello son los dos volúmenes dedicados a las iglesias gallegas en la obra colectiva dirigida por J. García Oro acerca de las diócesis españolas (GARCÍA ORO, J., Historia de las diócesis españolas, Madrid, 2002; v. 14 y 15), que además de sistematizar y sintetizar la bibliografía existente realiza nuevas e interesantes aportaciones, especialmente útiles para las iglesias de Lugo, Ourense y Tui y en casi todos los casos para los períodos moderno y contemporáneo.

«CUADERNOS DE ESTUDIOS GALLEGOS», Tomo XLIX, Fascículo 115, Santiago 2002. 
o no) que existieron en cada diócesis, cuáles fueron sus rentas, quienes y cuántos eran los clérigos que los servían, cuándo y de qué modo se aplicó a esta red beneficial la estructura de arciprestazgos y arcedianatos o cuántos y cuales beneficios fueron usufructuados por otras entidades y personas religiosas. Con estas carencias, el investigador tiende a tomar como referencia la geografía administrativa reciente a la que aplica criterios correctores tales como obviar las parroquias de nueva creación o reformular los límites de los actuales arciprestazgos. Una lectura atenta de las visitas diocesanas más completas procedentes del XVI y de textos como las Memorias del arzobispado de Santiago de Jerónimo del Hoyo proyectan una imagen del espacio diocesano que es más clara y completa pero, sobre todo muy diferente, al incorporar, por ejemplo, noticia de advocaciones, circunscripciones parroquiales y oratorios hoy desaparecidos. Es necesario, sin embargo, intentar retrotraer las noticias sobre la cuestión.

Por ello, la documentación relacionada con el cobro de las tasa denominada décima o subsidio del clero, que afectó a la casi totalidad de las personas e instituciones eclesiásticas, constituye una herramienta de gran interés y utilidad para subsanar estas deficiencias. Especialmente importantes resultan para el acercamiento a las diócesis gallegas hasta bien entrada la Edad Moderna -cuando comenzamos a disponer ya de las primeras visitas episcopales o arcedianales de cierta envergadura ${ }^{3}$.

\section{EL SUBSIDIO Y LA DÉCIMA}

\section{Características generales}

Las rentas procedentes de los bienes y derechos propiedad de las distintas instituciones eclesiásticas estuvieron sujetas, sobre todo a partir del siglo XIV, a tributación fiscal inicialmente y de modo esporádico e individual en beneficio de la Cámara Apostólica y más tarde de manera casi general y obligatoria también del tesoro real. En un proceso lento pero de creciente alcance se van ampliando el número de contribuyentes, las razones de tributación y la complejidad de los procesos y personas

${ }^{3}$ Las visitas pastorales en el ministerio del obispo y archivos de la Iglesia, Asociación de Archiveros de la Iglesia en España, Madrid, 1999.

«CUADERNOS DE ESTUDIOS GALLEGOS», Tomo XLIX, Fascículo 115, Santiago 2002. 
implicadas. De los gravámenes a que están sujetas las distintas entidades religiosas, el estudio de la décima y subsidio presenta gran interés pues supone un acercamiento a la relación de las iglesias diocesanas con la curia pontificia, ejemplifica de qué modo incide la creciente centralización aviñonense en las sedes y muestra cómo la hacienda real de Castilla fue, progresivamente, desviando las aportaciones gallegas -en realidad, de las de todas las iglesias del reino- en su beneficio.

Ya a principios del siglo XI, la administración fiscal del pontificado recibe el nombre de Cámara Apostólica; es también en este momento cuando se tienen las primeras noticias precisas sobre ingresos más o menos estables procedentes de diócesis fuera de Italia; desde el siglo siguiente, esta instancia centralizará todos los asuntos relativos a las finanzas de la sede pontificia ${ }^{4}$. A partir de este momento, los afanes de esta dependencia se volcarán en racionalizar la gestión y acrecentar las vías de ingresos; la maduración definitiva tiene lugar durante el período aviñonés cuando los acontecimientos ponen en serias dificultades al tesoro papal. Es entonces cuando se introducen nuevas tasas que son, además, de mayor alcance y cuando se maduran organigramas y procedimientos que incrementan considerablemente la eficacia de la recaudación.

Las tasas más antiguas son los servitia (communia y minuta), los pagos relacionados con el cumplimiento de la visita ad limina apostolorum y la porción de los bienes de los prelados difuntos que percibe el Papa (ius spolii). A ellos se unirá, porteriormente, la annata devengada por los

\footnotetext{
${ }^{4}$ A pesar de su antigüedad, siguen siendo básicos para el estudio de esta cuestión los estudios de FAVIER, J., Les finances pontificales a l'époque du Grand Schisme d'Occident (1378-1409), Paris, 1966; LUNT, W.E., Papal Revenues in the Middle Ages, New York, 1934; SAMARAN, C. \& MOLLAT, G., La fiscalité pontificale en France au XIVe siècle, Paris, 1905. Para el reino castellano v. FERNÁNDEZ CONDE, J. \& OLIVER, A., «La corte pontificia de Aviñón y la Iglesia española», en Historia de la Iglesia en España (siglos VIII-XIV) (Madrid, 1981); GOÑI GAZTAMBIDE, J., «El fiscalismo pontificio en España en tiempo de Juan XXII», Anthologica Annua 14 (1966): pp. 65-69; ZUNZUNEGUI, J., «La Cámara apostólica y el Reino de Castilla durante el Pontificado de Inocencio IV (1352-1362)», Anthologica Annua 1 (1953): pp. 154-184; asi como las páginas dedicadas por T. de AZCONA a este tema en AZCONA, T., «Reforma del episcopado y del clero en España en tiempo de los Reyes Católicos y de Carlos V (14751558)», en Historia de la Iglesia en España (Madrid, 1979), v. III-1, pp. 183-206. Sobre este tema se expondrán sólo los aspectos más generales puesto que ya ha merecido un buen número de estudios.
} 
beneficios de colación pontificia ${ }^{5}$. Todos -eclesiásticos y laicos- deben además realizar desembolsos de costo variable en concepto de tasas de cancillería o derechos por indulgencias ${ }^{6}$, tributos que se vuelven más gravosos durante el siglo XV cuando el valor de aquellos anteriormente más significativos (como los servicios) es rebajado.

El tributo de mayor alcance -sobre todo a medio plazo- son los subsidios solicitados por los papas a algunos prelados y diócesis con motivo de necesidades especiales de la Iglesia y pueden llegar a afectar directa o indirectamente a todo el clero diocesano ${ }^{7}$. Pueden ser solicitados al obispo o a los clérigos, aunque parece ser frecuente que los primeros acaben repercutiendo total o parcialmente el pago en los segundos. Suelen presentarse como dádivas caritativas - tanto el abonado al Papa como el entregado por la clerecía a su prelado- y las cantidades pagadas suelen ser proporcionales a las rentas globales del beneficio. Existen noticias sobre desembolsos de este tipo realizadas por arzobispos de Santiago: en 1326, Berenguel de Landoira -como responsable de la colecta en su provincia eclesiástica- abonó una importante cantidad para la lucha de la Iglesia contra los herejes milaneses ${ }^{8}$.

Con carácter en principio extraordinario, los papas comenzaron a cargar las rentas de los beneficios eclesiásticos con una tasa equivalente al $10 \%$ de los rendimientos. Es el tributo conocido como decima, inicialmente aplicado al auxilio de Tierra Santa y, más tarde, a las necesidades generales de la Iglesia ${ }^{9}$. Las primeras exigencias de este tipo tienen como finalidad financiar las Cruzadas y la primera solicitud de carácter general emana del IV Concilio de Letrán, gravando a todos los beneficios con un

\footnotetext{
${ }^{5} \mathrm{~V}$. nota supra.

${ }^{6}$ LUNT, Papal revenues; pp. 103-134.

${ }^{7}$ Ibid.; pp. 77-81. Según Samaran y Mollat (SAMARAN \& MOLLAT, La fiscalité; p. 56), los papas se limitaron a aprovechar una costumbre ya establecida por los obispos en sus diócesis al recaudar para necesidades puntuales aportaciones del clero diocesano; y en efecto, este tipo de peticiones -bajo la denominación de subsidio caritativo- son mencionadas en la documentación incluso en el siglo XV (GARCÍA Y GARCÍA, A., Synodicon hispanum. I, Galicia, Madrid, 1981; sínodos de Mondoñedo 1498 y 1502; Santiago, 1435, c.4).

${ }^{8}$ GÖLLER, E., Die Einnahmen der Apostolischen Kammer unter Johann XXII, Paderborn, 1905; pp. 500-501.

${ }^{9}$ SAMARAN \& MOLLAT, La fiscalité; pp. 12-22.
}

«CUADERNOS DE ESTUDIOS GALLEGOS», Tomo XLIX, Fascículo 115, Santiago 2002. 
$20 \%$ de sus rendimientos durante tres años. En adelante, con una duración variable y con una tasa de exacción también diferente serán otorgadas por papas o concilios para auxiliar a las necesidades de la guerra contra el infiel o para cubrir el déficit del tesoro pontificio. Se beneficiarán de ella de un modo creciente algunas haciendas reales, especialmente los reinos hispánicos que la reclamarán como ayuda indispensable para continuar la guerra contra los musulmanes de la Península. El interés conjunto de la Cámara Apostólica y de los Reyes por hacer de esta tasa un item estable e interesante de sus ingresos provocará una cierta modificación en la forma y en los modos de recaudación de la décima, que acabará cristalizando en el denominado subsidio ${ }^{10}$.

A efectos prácticos, algunos de los impuestos ya mencionados presentan ciertas dificultades pues no se trata de cobrar una cantidad fija y predeterminada a un número de personas y entidades previamente conocidas sino que es preciso calcular en el momento de cada recaudación quienes son objeto de tributación y qué cuantía debe reclamarse a cada uno. Para resolver este inconveniente la Cámara Apostólica desarrolla un procedimiento -la taxatio o tasación-, crea una figura administrativa que la supervisa y organiza el cobro -el colector o colectores-y divide la Cristiandad en demarcaciones -las colectorías-. Todo este sistema existe ya a finales del siglo XIII y gana considerable eficacia en el XIV: los colectores generales designan a una o varias personas que en cada diócesis se informan de los beneficios y sus rendimientos bajo el juramento que realizan sus poseedores y determinan la cantidad a pagar; esta estimación es revisada por el colector quien valorará la existencia o no de fraude $u$ ocultación ${ }^{11}$. La relación resultante -verdadera guía de la geografía económica y fiscal de cada diócesis- es utilizada en la recaudación de items de valor proporcional al montante de los ingresos.

Respecto a la décima -sin duda el canon con más contribuyentesGregorio VII y Bonifacio VIII establecen de modo preciso el cauce de una tributación a la que están sujetos todos los que disfrutan de algún tipo de patrimonio eclesiástico. Existen, no obstante, exenciones: los hospita-

\footnotetext{
${ }^{10}$ Sobre los pormenores de la derivación de esta tasa hacia el tesoro real castellano y los procesos relacionados véase infra.

${ }^{11}$ LUNT, Papal revenues; p. 74; SAMARAN \& MOLLAT, La fiscalité; pp. 112-114.
} 
les y casas para pobres y enfermos (incluyendo a la Orden Hospitalaria de San Juan de Jerusalén), religiosos que viven de la limosna y la predicación (órdenes mendicantes) y los clérigos seculares cuyos ingresos son inferiores a 7 florines anuales. En 1301 el papa Bonifacio otorga un edicto sobre el tema en el que con precisión y detalle se desglosa el modo en que se realiza el cálculo y el tipo de ingresos que se computan (por ejemplo, cómo deben valorarse los procedentes de las pesquerías o los prados) y cuáles no han de ser tenidos en cuenta (como lo gastado en el sustento de la comunidad monástica o en la reparación de iglesias y ciertas edificaciones). Dispone también que el pago debe realizarse en dinero contante de la moneda común de la tierra, cuáles son las penas en que incurrirán quienes se resistan o cometan fraude y cómo ha de conducirse el colector a la hora de ejecutarlas ${ }^{12}$. Establece, asimismo, dos vías para deducir la cantidad a pagar en cada beneficio - que una vez elegida no podrá modificarse-: a priori sobre una estimación de los ingresos anuales o bien $a$ posteriori sobre el valor real de lo percibido ${ }^{13}$.

La actividad de los colectores apostólicos en el reino castellano es conocida, sobre todo, a partir del período de Aviñón, cuando todo este engranaje administrativo comenzó a tomar cuerpo y a ganar en eficacia aunque, según todos los indicios, su experiencia distó mucho de ser satisfactoria ${ }^{14}$. Las diócesis gallegas quedaron quedaron incluidas en la colectoría del norte del reino, la de Burgos.

En el proceso de formación de los estados bajomedievales $-\mathrm{y}$ a través de ellos los modernos-, la creación de administraciones hacendísticas y la consolidación de las bases financieras son dos fenómenos de gran inte-

\footnotetext{
${ }^{12}$ Recogido en la legislación canónica en Extravagantes Comunes, lib. 3, tit. VII, cap. un.

${ }^{13}$ Esta última circunstancia, unida a posibles maniobras de ocultación y resistencia, contribuye a alargar los procesos de recaudación llevados a cabo en cada diócesis.

${ }^{14} \mathrm{La}$ evolución general, datos concretos y documentación relacionada en FERNÁNDEZ ALONSO, J., «Los enviados pontificios y la colectoría de España de 1466 a 1475», Anthologica Annua 2 (1954): pp. 51-122; FERNÁNDEZ CONDE \& OLIVER, «La corte pontificia», pp. 400-403; GOÑI GAZTAMBIDE, «El fiscalismo», pp. 65-99; ZUNZUNEGUI, «Cámara Apostólica», pp. 154-184; ZUNZUNEGUI, J., «Las cuentas de los colectores apostólicos en Castilla durante el pontificado de Inocencio IV», Anthologica Annua 14 (1966): pp. 441-461. Desde una óptica muy diferente NIETO SORIA, J.M., Iglesia y génesis del Estado Moderno en Castilla, Madrid, 1993; pp. 6482 y $314-315$.
}

«CUADERNOS DE ESTUDIOS GALLEGOS», Tomo XLIX, Fascículo 115, Santiago 2002. 
rés. En el caso castellano, los ingresos del clero aparecen desde muy pronto como objeto de apetencia de los oficiales de la Corona. Si bien existen noticias anteriores, según Nieto Soria, este proceso de fiscalización de los ingresos eclesiásticos por la Corona tiene lugar entre 1252 y 1369 , momento en el cual el modelo impositivo está plenamente configurado. Las figuras hacendísticas más importantes son las tercias reales, las décimas y subsidios y, sobre todo a partir de finales del siglo XV, la Cruza$\mathrm{da}^{15}$. El primer precedente claro de esta desviación en beneficio de las arcas regias es la concesión de Inocencio IV a Fernando III de la sexta parte de las rentas decimales percibidas en el reino. Son las llamadas tercias reales que acabarán siendo renovadas anualmente y serán un ingreso estable de la hacienda real ${ }^{16}$.

La décima, tasa esporádica equivalente a la décima parte de los ingresos eclesiásticos destinada a sufragar los gastos pontificios generados por la guerra en Tierra Santa, acabará siendo un ingreso corriente y estable del tesoro real castellano. La causa general esgrimida por el pontificado para su imposición (la lucha contra el infiel) es aducida por los sucesivos monarcas que consideran inapropiado desviar estas cantidades hacia otros frentes de guerra siendo que en su reino existe una cruzada propia contra los musulmanes ${ }^{17}$. Con la intención clara de fiscalizar las rentas eclesiásticas y financiar las campañas andaluzas, la Corona castellana busca y encuentra - cada vez con mayor frencuencia- privilegios pontificios que le permiten disfrutar del diezmo del clero.

La historia de la décima es algo más compleja que la de las otras formas impositivas del tesoro real. Es siempre fruto de un privilegio pontificio, las más de las veces nacido tras una dificultosa negociación entre el pontificado y los embajadores castellanos ${ }^{18}$. Puede concederse por un año o por un período de ellos, pero es siempre fruto de una concesión graciosa del

${ }^{15}$ NIETO SORIA, Iglesia; pp. 312-313. Sobre la Cruzada v. GOÑI GAZTAMBIDE, J., Historia de la bula de cruzada, Vitoria, 1958.

${ }^{16}$ LADERO QUESADA, M.A., El siglo XV en Castilla. Fuentes de renta y política fiscal, Barcelona, 1982; pp. 32-35, 50 y 190-191; NIETO SORIA, Iglesia; pp. 317-321.

${ }^{17}$ Habría que tener en cuenta también otras consideraciones tales como que la insistente actividad de los colectores pontificios tiene como consecuencia la salida del reino de importantes cantidades de moneda acuñada en oro.

${ }^{18}$ NIETO SORIA, Iglesia; pp. 324-337; GOÑI GAZTAMBIDE, Bula de cruzada; loc. cit.

«CUADERNOS DE ESTUDIOS GALLEGOS», Tomo XLIX, Fascículo 115, Santiago 2002. 
Papa que, en principio, se resiste a que los reyes disfruten en exclusiva de estas ganancias; por ello, y hasta el tiempo de los Reyes Católicos, una parte de lo localmente recaudado es recibido por los colectores pontificios ${ }^{19}$. En ocasiones, la concesión pontifical se relaciona con una imposición reclamada en toda la Cristiandad otras veces, en cambio, se trata de décimas específicas limitadas al reino castellano. Desde 1309 y aún más allá de la toma de Granada tributa el clero castellano en beneficio de las empresas guerreras de sus reyes. El pontificado aún a regañadientes debió encontrar positiva esta evolución pues, al parecer, la recaudación de este tributo decimal resultó siempre dificultosa y encontró importantes resistencias que parecían salvables con la intervención de la autoridad regia ${ }^{20}$.

Las expansivas necesidades financieras de la Hacienda real hacen inevitable el recurso a los ingresos beneficiales por la vía de los préstamos y pedidos especiales pero esta creciente presión acaba generando malestar entre el estamento eclesiástico del reino que, como respuesta, se junta cada vez con mayor frecuencia en reuniones y asambleas en las que la tributación parece ser punto importante. Estas asambleas o congregaciones del clero - a las que se convocan y acuden obispos y representantes de los cabildos castellanos- se erigirán como interlocutor válido y mediador imprescindible para la colecta de esta tasa. Son ellas las encargadas de negociar el monto final que debe aportar el estado eclesiástico a las arcas papales y reales ${ }^{21}$.

\footnotetext{
${ }^{19}$ Los Reyes Católicos conseguirán eliminar este requisito al ofrecer durante la negociación un importante donativo a la Cámara Apostólica a modo de compensación.

${ }^{20}$ NIETO SORIA, Iglesia; pp. 314-315; LINEHAN, P., The Spanish Church and the Papacy in the Thirteenth Century, Cambridge, 1971; pp. 156-160. Quizás debería considerarse como un factor decisivo en la nueva postura pontificia el creciente intervencionismo de la Corona en el nombramiento de obispos y altos dignatarios que -al participar plenamente en los asuntos políticos del reino- quizás se mostraron más inclinados a comprender y compartir las intenciones y necesidades del tesoro real (sobre esta cuestión v., además de la ya mencionada obra del Prof. Nieto Soria, AZCONA, T., La elección y reforma del episcopado español en tiempos de los Reyes Católicos, Madrid, 1960).

${ }^{21}$ AZCONA, T., «Las asambleas del clero de Castilla en el otoño de la Edad Media», en Miscelánea José Zunzúnegui (1911-1974) (Vitoria, 1975), pp. 203-245; SÁNCHEZ HERRERO, J., «Los concilios provinciales y los sínodos diocesanos españoles (12151550)», Quaderni Catanesi di Studi Classici e Medievali 3 (1981), pp. 131-181 y 4 (1982), pp. 111-198.
}

«CUADERNOS DE ESTUDIOS GALLEGOS», Tomo XLIX, Fascículo 115, Santiago 2002. 
Asi, lo que inicialmente fue un gravamen sobre las rentas generadas por cada beneficio cuyo monto final en cada diócesis y en todo el reino no puede calcularse a priori acaba convirtiéndose para cada contribuyente en una obligación de abonar una parte de una cantidad final predeterminada para todo el reino. Es decir, la cantidad a pagar no está en función de los ingresos beneficiales sino de la suma total que las iglesias del reino deben reunir y que previamente han pactado ${ }^{22}$. De ahí el nombre con el que los contemporáneos pasarán a designar a esta tasa: el subsidio.

El estudio del tributo décimal en cualquier diócesis ha de abordarse desde unos presupuestos distintos a los planteados para el acercamiento a los restantes items debidos a la Cámara Apostólica. Ello es así por la amplitud del grupo de contribuyentes, por el modo en que se organiza la recaudación y valoración de las cantidades, por su cada vez mayor frecuencia y, finalmente, porque este impuesto sufre a lo largo de su historia una importante modificación tanto en sus aspectos económicos y organizativos como en el del nombre por el que se conoce. La sucesión total de las décimas que llega a pagar el clero del reino de Castilla está aún por establecer, pero a tenor de los datos diponibles la corona pudo beneficiarse de esta tasa en múltiples ocasiones en la Baja Edad Media ${ }^{23}$ : en $1274,1309,1328,1340,1343,1346,1373,1397$ y 1399, 1424, 1430, 1431 у $1433,1457,1458,1460,1463,1472-73,1474-79,1482,1485$, $1487,1489,1490,1491,1492,1494,1495$ y $1497,1500,1501^{24}$.

Las primeras noticias apuntan a que la décima es exigida de modo puntual a algunas diócesis a través de sus prelados, aunque puede ser también que el Papado encomiende a uno o varios obispos de Castilla la recaudación de esta tasa en un distrito o en todo el reino. Y, aunque la parte que lleva el rey de lo recaudado es cada vez mayor, los agentes

\footnotetext{
${ }^{22}$ La más conocida de estas negociaciones es, sin duda, la llevada a cabo con Rodrigo Borja (GOÑI GAZTAMBIDE, Bula de cruzada; pp. 423-427; FERNÁNDEZ ALONSO, J. «Los enviados pontificios y la colectoría de España de 1466 a 1475», pp. 51-122).

${ }^{23}$ Lo cierto es que los ritmos de imposición distan mucho de estar claros. Datos aproximados y noticias pueden encontrarse en las ya citadas obras de Nieto Soria y Ladero Quesada, asi como en CASADO ALONSO, H., «La contribución de la diócesis de Burgos a la Hacienda Real en el siglo XV», en Historia de la Hacienda Española (épocas antigua y medieval). Homenaje al Prof. García de Valdeavellano (Madrid, 1982), pp. 175-191.

${ }^{24}$ Datos tomados de las obras citadas en la nota anterior.
} 
pontificios siguen ejerciendo, lo que indica que la recaudación local permanece en manos de obispos y cabildos que pagan a los representantes reales y papales la parte que les corresponde ${ }^{25}$. Los colectores localmente designados suelen ser canónigos de los respectivos lugares ${ }^{26}$ que abonan la cantidad correspondiente al colector general o a sus agentes en persona o a través de representantes. Los indicios apuntan a que generalmente la estimación de lo que cabe a cada contribuyente es decidida por cada iglesia, siendo ésta la opción más razonable puesto que es la administración local quien dispone de información de primera mano sobre el valor de los beneficios.

La llegada a las distintas diócesis del documento que solicita la cuota diocesana pone en marcha un complejo proceso de tasación y recaudación una de cuyas fases más interesantes -a nuestros efectos- es la puesta al día de la información relativa al número y valor de los beneficios.

\section{La décima y el subsidio en las diócesis gallegas}

Son muy escasas las noticias sobre recaudaciones en tierras gallegas y se nos remite a órdenes directas dadas a prelados o personas puntuales para que lleven a cabo ciertos cometidos en nombre de la curia romana como la que originó la actuación del arzobispo D. Berenguel de Landoira como ejecutor del cobro de la parte pontificia del espolio de los bienes de Simón, obispo de Tui ${ }^{27}$; la fiscalización de los del compostelano por el bracarense $\mathrm{e}^{28} \mathrm{o}$ la intervención conjunta de los prelados compostelano y auriense -en 1354 por orden de Inocencio IV- sobre los bienes de D. Álvaro de Biedma (fallecido en 1351 ${ }^{29}$. Informaciones incompletas -ya sea por no referir los conceptos de cobro o por no desglosar las diócesis

\footnotetext{
${ }^{25}$ No ocurre asi, por ejemplo, con las tercias reales (las 2/9 partes del ingreso decimal que son dadas al rey). Este ingreso es recaudado directamente por los agentes de la real hacienda.

${ }^{26}$ Por ejemplo, véase la relación publicada en LINEHAN, P., «The Church, the economy and the reconquista in the early fourteenth-century Castile», Revista española de teología 43 (1983): pp. 300-303.

${ }^{27}$ GÖLLER, Johann XXII; pp. 486-487. Fallecido este prelado en 1326, el pago en la Cámara tiene lugar en 1328 a través de un agente pontificio enviado a Portugal.

${ }^{28}$ Ibidem, p. 502.

${ }^{29}$ El valor de lo recaudado ascendió a 31.398 mrs (ZUNZUNEGUI, «Cámara Apostólica», pp. 167-168).
} 
cotizantes- se encuentran en los informes contables y la correspondencia de los colectores ${ }^{30}$.

La primera noticia clara sobre el cobro de la décima es de 1278 , cuando Nicolás III en carta dirigida al obispo de Oviedo y recaudador de la décima -concedida al rey- en el reino de Castilla le conmina a no exigirla a los clérigos de los arciprestazgos de Xanrozo y Abegondo de la archidiócesis de Santiago pues no alcanzan ese año sus ingresos las 7 libras mínimas requeridas $^{31}$. Consta, por evidencias precisas, la resistencia compostelana a entregar las décimas promulgadas en las primeras décadas del siglo XIV y que en 1312 Ramón de Montrós -recaudador pontificio-hubo de personarse en Santiago para obligar al pago ${ }^{32}$; también que las estimaciones realizadas sobre el valor de los beneficios no siempre suscitan unanimidad: en 1318, el sucesor de Montrós, Raimundo de Siena, se ve impelido a aceptar una recaudación sobre la base de los documentos se le presentan y cuya veracidad pone en duda $^{33}$. No se conocen problemas en referencia a un pago realizado por este concepto en $1329^{34}$. La responsabilidad de las autoridades locales y la permanente dificultad de la recaudación se ve confirmada en 1336 cuando Benedicto XII manda al arzobispo que devuelva las cantidades tomadas a ciertas personas eclesiásticas para la décima en beneficio de Tierra Santa ${ }^{35}$. Hasta final de siglo, apenas hay información disponible para el estudio de esta tasa aunque nos consta la recaudación de varias décimas en Castilla, la mayor parte de las cuales beneficia a la

${ }^{30}$ NIETO SORIA, Iglesia; p. 71; ZUNZUNEGUI, «Las cuentas», pp. 441-461. El período más conocido es la segunda mitad del siglo XV cuando disponemos incluso de pormenorizados relatos sobre los avatares de la recaudación de estos agentes en Galicia (FERNÁNDEZ ALONSO, J., Legaciones y nunciaturas en españa de 1466 a 1521: v. I (1466-1486), Roma, 1963).

${ }^{31}$ DOMÍNGUEZ SÁNCHEZ, S., Documentos de Nicolás III (1277-1280) referentes a España, León, 1999; doc. 26; se envia copia, asimismo al arzobispo y cabildo de Santiago asi como al clero diocesano (docs 17 y 20).

${ }^{32}$ LINEHAN, «The church», pp. 277-299 y en general todo este artículo. Debe tenerse en cuenta al valorar estos acontecimientos la delicada situación de la Iglesia y tierra de Santiago hasta la llegada de D. Berenguel de Landoira.

${ }^{33}$ Ibid.: pp. 291-292, la tasación en apéndice 2. En su informe, Serra -una de cuyas misiones es revisar la gestión de su predecesor- hace constar que ha desaparecido buena parte de la documentación local justificativa (las tasaciones y recibos).

${ }^{34}$ Archivo de la Catedral de Santiago (ACS), Tumbillo de Concordias: $\mathrm{f}^{\mathrm{o}} 300 \mathrm{r}-300 \mathrm{v}$.

${ }^{35}$ VIDAL, J.M., Benoit XII (1334-1342). Letteres communes, Paris, 1911; v. I, 251. 
Corona $^{36}$. De modo que hasta la segunda mitad del siglo $\mathrm{XV}$, cuando la décima ha pasado a convertirse plenamente en un subsidio la mayor parte de las veces en beneficio de las arcas reales, no es posible encontrar noticias muy consistentes y esclarecedoras para el estudio de esta cuestión.

En efecto, son mejor conocidas las actuaciones de los colectores de este período ${ }^{37}$, sobre todo la de Leonoro de Leonori (desarrollada a partir de 1465) de la que disponemos de un interesante número de documentos que nos permiten reconstruir la actividad tipo de uno de estos agentes puesto que recibió entregas correspondientes a las tasas habituales debidas al pontificado, a las resultantes de la predicación de la bula de Cruza$\mathrm{da}^{38} \mathrm{y}$ al subsidio del clero. Este nuncio y colector acude al reino castellano provisto de escritos que acreditan su condición, entre ellos cartas de presentación y credenciales dirigidas a los más importantes prelados y personajes de la corte. En este caso concreto, recibe también instrucciones precisas un tema espinoso: conseguir la liberación de los prelados de Santiago $^{39}$, Cuenca y Osma. Dispone también de licencias que le permiten designar a los subcolectores, notarios y otros agentes con los que llevar a cabo su cometido e instrucciones precisas de cómo realizarlo. Leonori dispone de capacidad para fiscalizar la actividad de otros subcolectores como, por ejemplo, a Fernando Basanta, canónigo de Santiago que actuó como colector y nuncio en Galicia y Asturias en años anteriores ${ }^{40}$. Y pue-

${ }^{36}$ Sobre la historia de la décima en Castilla y su relación con la hacienda regia v. GOÑI GAZTAMBIDE, Bula de cruzada; pp. 323-470; LADERO QUESADA, El siglo $X V$; pp. 191-212; LADERO QUESADA, M.A., La hacienda real de Castilla en el siglo $X V$, La Laguna, 1973; pp. 234-238; LADERO QUESADA, M.A., Fiscalidad y poder real en Castilla (1252-1369), Madrid, 1993; pp. 191-216 y 203-207; NIETO SORIA, Iglesia; pp. 322-342.

${ }^{37} \mathrm{~J}$. Fernández Alonso recoge en sus obras un gran numero de testimonios referentes a las legacías de Leonoro de Leonori, Rodrigo Borja, Francisco Ortiz y Nicolás Franco.

${ }^{38}$ GOÑI GAZTAMBIDE, Bula de cruzada, ; LADERO QUESADA, La Hacienda; pp. 227-234.

${ }^{39}$ Poco después de su llegada a Santiago, D. Alonso de Fonseca II fue secuestrado por Bernal Eáns de Moscoso quien lo retuvo durante aproximadamente dos años (LÓPEZ FERREIRO, A., Historia de la Santa A.M. Iglesia de Santiago de Compostela, Santiago de Compostela, 1898-1909; v. VII, pp. 249 y ss.).

${ }^{40}$ Sobre su legacion v. FERNÁNDEZ ALONSO, J., «Los beneficios encorozados en Galicia en el siglo XV. Fernando Basanta, nuncio apostólico (1464)», Anthologica Annua 28-29 (1981-82): pp. 553-579.

«CUADERNOS DE ESTUDIOS GALLEGOS», Tomo XLIX, Fascículo 115, Santiago 2002. 
de y debe conminar a aquellos que se resisten al pago de los items debidos a la Cámara. Tenemos también el documento contable que presenta como justificación de sus actividades durante los años 1471-76 ${ }^{41}$ : entre mayo y octubre de 1473 recibe de Diego Tamayo, deán de Santiago, los 150 ducados áureos que debe abonar a la Cámara; a lo largo de 1474 recibe de manos de Lucas García -recaudador en Galicia-importantes cantidades procedentes de la predicación de la bula de Cruzada en Asturias, Santiago y Ourense $\mathrm{e}^{42}$ y al año siguiente $132.560 \mathrm{mrs}$ resultantes de la venta de diversos bienes y objetos que corresponden al Papado ${ }^{43}$; interesantes son también las relaciones de gasto o pérdida dadas por Leonori, que se hacen eco de los pormenores e inconvenientes de la recaudación en Galicia ${ }^{44}$.

Los detalles de la recaudación del subsidio y la décima en el territorio diocesano son conocidos sólo de modo superficial. Tanto si acuden representantes capitulares a las asambleas del clero como si no, la noticia con lo que debe aportarse es recibida en cada sede, junto con los detalles y cualquier otra instrucción relacionada con el tema ${ }^{45}$. Las cantidades concretas que en cada reparto corresponden a esta diócesis se deciden en estas congregaciones -si bien en el reparto local se ven incrementadas con lo necesario para gastos:

\begin{tabular}{lcccc}
\hline & $\mathbf{1 4 1 5}$ & $\mathbf{1 4 3 0}$ & $\mathbf{1 4 8 2}$ & $\mathbf{1 4 9 4}$ \\
\hline Santiago & 1.928 & 9.240 & 6.096 & 9.674 \\
Ourense & 468 & 3.215 & 1.911 & 2.865 \\
Lugo & 212 & 1.860 & 805 & 1.291 \\
Mondoñedo & 433 & 1.860 & 1.700 & 2.657 \\
Tui & 282 & 642 & 595 & 955 \\
\hline
\end{tabular}

Relación de florines aragoneses aportados por las diócesis gallegas ${ }^{46}$.

\footnotetext{
${ }^{41}$ FERNÁNDEZ ALONSO, Legaciones; doc. 121.

${ }^{42}$ Ibid. doc. 122.

${ }^{43}$ Ibid. doc. 127.

${ }^{44}$ Ibid. Doc. 124 y 131 (Item fuerunt perdite multe bulle deposite ac credite per thesaurarios et etiam sublate et etiam combuste in Galicia, doc. 131).

${ }^{45}$ Asi ocurre, por ejemplo, con las reuniones de Salamanca (1462) y Córdoba (1483) de las que no hay noticia de presencia compostelana pero sí puntual conocimiento de su contenido (LÓPEZ FERREIRO, Historia; v. VII, apéndices, p. 129 y 339-440).

${ }^{46}$ Datos tomados de NIETO SORIA, Iglesia; p. 75; LADERO QUESADA, El siglo $X V ;$ p. 194.
}

«CUADERNOS DE ESTUDIOS GALLEGOS», Tomo XLIX, Fascículo 115, Santiago 2002. 
Las noticias locales hasta bien entrada la Edad Moderna son también escasas. La más antigua -recogida en el sínodo mindoniense de 1350- se hace eco de las resistencias al pago y de la denuncia de excomunión que promulgó el recaudador diocesano contra los clérigos rebeldes ${ }^{47}$. Sabemos que al año siguiente se concertó en esta diócesis un acuerdo entre el obispo y el abad del monasterio de Lourenzá que se resistía a contribuir como el resto de la clerecía ${ }^{48}$, hay noticia también de varios pagos realizados en 1410 al subcolector diocesano no sabemos en qué concepto ${ }^{49} \mathrm{y}$ de que, en 1474, se dictó excomunión contra el cabildo catedralicio por no entregar su parte en el plazo fijado ${ }^{50}$ asi como de una reclamación hecha en 1476 por el provisor para que se le den garantías por valor de los 2.100 mrs que prestó al cabildo para el pago del subsidio ${ }^{51}$; en 1478 , se promulgó una sentencia que puso fin a las diferencias existentes respecto al pago del monasterio de Santa María de Montefaro ${ }^{52}$.

En Ourense, tiene lugar en 1373 una información acerca de cómo ha de realizarse el reparto de la contribución, pues se ha perdido la tasación escrita ${ }^{53}$, conservamos dos tasaciones realizadas en los años 1424 y $1439^{54}$, asi como el alzamiento de una excomunión fulminada contra el cabildo por no abonar el subsidio ${ }^{55}$. En 1441, los estatutos sinodales publican severas amenazas contra los clérigos que se resisten al pago del subsidio pontificio ${ }^{56}$. No sólo se documentan incidentes relacionados con el impago de los contribuyentes sino también conflictos acerca del esta-

${ }^{47}$ GARCÍA Y GARCÍA, Synodicon; sín. mindoniense de 1350, canon un.

${ }^{48}$ El documento está muy deteriorado de modo que el contenido del acuerdo no ha podio ser establecido (AHN, Clero, Carp. 1110, $\mathrm{n}^{\circ} 19$ ).

${ }^{49}$ CAL PARDO, E., Catálogo de los documentos medievales, escritos en pergamino, del archivo de la Catedral de Mondoñedo (871-1492), Lugo, 1990; doc. 1311-15.

${ }^{50}$ Ibid.; doc. 145.

${ }^{51}$ CAL PARDO, E., Catálogo-regesta de la documentación del siglo XVI del Archivo de la Catedral de Mondoñedo, Santiago de Compostela, 1992; doc. $\mathrm{n}^{\circ} 162$.

${ }^{52}$ CAL PARDO, Catálogo pergaminos; doc. 200

${ }^{53}$ DURO PEÑA, E., Catálogo de los documentos en pergamino del Archivo de la Catedral de Orense (888-1554), Orense, 1973; doc. $n^{\circ} 881$.

${ }^{54}$ VAQUERO DÍAZ, M.B., Colección diplomática do mosteiro benedictino de San Salvador de Celanova (Ourense) (séculos XIII, XIV e XV) (Universidade de Vigo, 2001), doc. $\mathrm{n}^{\circ} 264$ y 315 .

${ }^{55}$ GARCÍA Y GARCÍA, Synodicon, Sínodo Auriense de 1441.

${ }^{56}$ Ibid.; sín. auriense 1441, c.un. 
blecimiento de la cuota, es decir, sobre la derrama: en 1445 el juez episcopal zanja la cuestión establecida entre el clero diocesano y algunas abadías compostelanas acerca del reparto ${ }^{57}$. El pago en sí y quien debe hacerlo en caso de fallecimiento del beneficiado fue también objeto de la legislación sinodal ${ }^{58}$.

La documentación capitular de Santiago registra el pago de importantes cantidades de dinero a colectores apostólicos quizás como fruto de esta tasa entre 1391 y $1393^{59}$; y casi $15.000 \mathrm{mrs}$ se entregan en 1398 al enviado regio que se presenta en Santiago a recibir la parte que le corresponde en la décima de $1397^{60}$. En esta diócesis, la recaudación parece estar en manos del obispo y cabildo, que no siempre consiguen llevar a cabo pacíficamente su cometido ${ }^{61}$.

Las informaciones referentes a Tui son más bien escuetas y se refieren a un acuerdo entre obispo, cabildo, abades y clerecía sobre cómo realizar el reparto del subsidio otorgado al rey por Eugenio IV $(1440)^{62}$ y a la recepción en cabildo de una petición del colector Leonoro de Leonori y el pago de la cantidad correspondiente a esta institución $(1460)^{63}$. No hay informaciones procedentes de la iglesia lucense.

En la década de los años 1480, actuó en Galicia como recaudador en Galicia Pedro de Altamirano, canónigo de Toledo y protonotario apostólico, quien ejerció su cometido con una eficiencia ciertamente expeditiva. Las informaciones de su actividad en la diócesis compostelana lo retratan como colector celoso que no duda en embargar los ingresos arzobispales ${ }^{64}$ y acometer una reforma en profundidad de los documentos de tasación. En efecto, lleva a cabo -al menos en Santiago y Mondoñedo- procesos de

\footnotetext{
${ }^{57}$ DURO PEÑA, Catálogo; doc. 1300.

${ }^{58}$ GARCÍA Y GARCÍA, Synodicon; Constituciones Antiguas de Our., c. 85.

${ }^{59}$ CABANA OTERO, A., O Tombo H da Catedral de Santiago de Compostela. Documentos anteriores a 1399 (Tese de licenciatura, Universidade de Santiago de Compostela, 2000), doc. $\mathrm{n}^{\circ} 2,3,4$ y 45.

${ }^{60}$ Ibidem doc. $\mathrm{n}^{\circ} 265$.

${ }^{61}$ Sobre la recaudación del subsidio en Santiago v. VÁZQUEZ BERTOMEU, M., «La iglesia de Santiago hacia 1500: el libro I del subsidio», (en prensa).

${ }^{62}$ Archivo de la Catedral de Tui (ACT), Pergaminos 10/18.

${ }^{63}$ ACT, Paraminos, XIII, f $\mathrm{f}^{4}$ 47-50r.

${ }^{64}$ Sobre esta intervención de Altamirano en Santiago y el libro I del Subsidio -que fue elaborado a instancia suya-v. VÁZQUEZ BERTOMEU, «La Iglesia de Santiago»,
} 
información cuya finalidad más evidente es el establecimiento de un nuevo arancel contributivo que, a todas luces, parece más ventajoso para la Corona $^{65}$. No es posible saber, en estos momentos, si este tipo de investigaciones se llevaron a cabo en las demás diócesis gallegas.

De todo este cúmulo de informaciones se deduce, sobre todo, la importancia concedida al proceso de tasación pues del establecimiento del reparto depende en buena medida la correcta recaudación del tributo ya que puede minimizar las reclamaciones y resistencias al pago. Una estimación realista permitirá a la administración real conocer mejor los límites tributarios de su clero y constituirá una herramienta fundamental a la hora de entablar una negociación sobre la cantidad a solicitar al Papado o al clero.

\section{LAS TASACIONES}

Asi pues, para llevar a cabo la recaudación de la décima o subsidio, en cada diócesis debe decidirse quienes son los contribuyentes y cuánto ha de pagar cada uno. El resultado final de esta investigación es un escrito que contiene la relación de beneficios sujetos a contribución y la cantidad que cada uno debe aportar. Es el punto final de un largo proceso informativo en el que intervienen diversas instancias y personas; a su vez, es el inicio e instrumento fundamental de otra operación (la recaudatoria), que incluye la actualización del padrón y la ejecución del cobro. Disponemos para ello de 4 piezas documentales elaboradas en Ourense (2), Santiago y Mondoñedo ${ }^{66}$.

${ }^{65}$ El clero compostelano protestó fuertemente la valoración hecha por Altamirano pues, al parecer, la tasa individual resultó más alta que las anteriormente establecidas; esta opinión fue, al menos en cierta medida, compartida por el protonotario (le costava, porque avia fecho pesquisa de los valores de los benefiçios e rentas de todo este arçobispado e rentas del cabildo e clerizia pertenesçentes, ellos aver sido mucho agraviados e los agraveos en su apelaçion expremidos seer verdaderos e justos (ACS, Actas Capitulares II, $\mathrm{f}^{\mathrm{0}}$ 93r-94r). La estimación realizada en Mondoñedo fue también protestada (CAL PARDO, E., Colección diplomática medieval do arquivo da catedral de Mondoñedo, Santiago, 1999; doc. 206).

${ }^{66}$ VAQUERO DÍAZ, Celanova, doc. 264 y 315; CAL PARDO, Colección diplomática; doc. 206; VÁZQUEZ BERTOMEU, «La Iglesia de Santiago».

«CUADERNOS DE ESTUDIOS GALLEGOS», Tomo XLIX, Fascículo 115, Santiago 2002. 


\section{Autoría}

Según se deduce de la documentación conservada, la confección de este arancel fiscal se rige en cada diócesis por una costumbre propia que, no obstante, debe tener como referencia la legislación pontificia al respecto. Es evidente que Santiago, Mondoñedo, Ourense y Tui -iglesias cuyos documentos permiten reconstruir este aspecto-siguen procedimientos distintos. En Santiago, la derrama es llevada a cabo por arzobispo y cabildo, que designan conjuntamente a los subcolectores diocesanos. Según parece cabe a estos personajes realizar el cálculo detallado de lo que ha de pagar cada contribuyente ${ }^{67}$, llevar a cabo la recaudación y hacer frente a posibles imprevistos y reclamaciones.

En Ourense, en cambio, existe una tasación antigua, posiblemente fruto de un acuerdo, que divide a los contribuyentes en tres grupos, cada uno de los cuales debe hacer frente a un tercio de la cantidad total a pagar: abadías exentas (de la diócesis y de fuera de ella pero con granjas en el territorio diocesano ${ }^{68}$ ), abadías no exentas y, finalmente, obispo, cabildo y clero diocesano ${ }^{69}$; los dos escritos conservados del siglo XV son testimonios notariales del pacto alcanzado por instituciones, obispo, cabildo y clero. Ambos son, en realidad, una actualización y puesta por escrito del acuerdo inicial entre los diversos sectores de cotización.

Con motivo de la décima de 1440, en la iglesia tudense se establece un nuevo sistema que supone que obispo y cabildo pasarán a formar parte del grupo de contribuyentes y que, como todos los demás, lo harán en función de su renta; todo el clero cotizará según los valores establecidos por una asamblea a la que se convocarán a los abades y a los arciprestes ${ }^{70}$;

${ }^{67}$ ACS, Actas Capitulares I, $f^{\circ} 210 v-212 r$ y Actas Capitulares II, $f^{\circ} 116 r$.

${ }^{68} \mathrm{El}$ interés de la iglesia ourensana por incluir a estas instituciones externas tiene su origen sin duda en la entidad de sus propiedades, dada la gran cantidad de tierras vinícolas en este territorio y la fuerte implantación de los monasterios de toda Galicia en estas zonas, sobre todo el Ribeiro del Avia y del Miño.

${ }^{69}$ DURO PEÑA, Catálogo; doc. no 881; VAQUERO DÍAZ, Celanova, doc. 264 y 315.

${ }^{70}$ ACT, Pergaminos 10/18. Parece difícil admitir que obispo y cabildo no hayan cotizado hasta este momento por lo que debemos pensar que o bien dejaron de hacerlo temporalmente -quizás a causa de una acusada merma de ingresos tras el Cisma o los conflictos con los caballeros de la diócesis- o bien que lo hacían de un modo distinto que fue considerado insatisfactorio por el resto de la clerecía.

«CUADERNOS DE ESTUDIOS GALLEGOS», Tomo XLIX, Fascículo 115, Santiago 2002. 
es también un testimonio notarial de lo estipulado. Quizás en las demás iglesias existieron negociaciones en este sentido (incluso en Santiago), sobre todo para fijar la participación de las grandes instituciones en la derrama diocesana ${ }^{71}$.

Caso distinto son las tasaciones confeccionadas por orden de Pedro de Altamirano en Santiago y Mondoñedo; tal y como consta en los testimonios con ellas relacionados, son fruto de la actividad del protonotario que llevó a cabo una información previa sobre los beneficios, revisó el instrumento resultante y lo reforzó con su autoridad y validación.

\section{Recopilación y elaboración de la información}

En cualquier caso, parece evidente que este reparto se realiza teniendo como referencia inevitable el número y valor anual de los beneficios, pues la tasa parece establecerse en todos los casos según a renda e cantidade de cada huun benefiçio. Para realizar la tasación es necesario, por lo tanto, establecer el padrón de contribuyentes y fijar la cuota de cada uno, previo conocimiento de su renta anual (lo que hoy llamaríamos base imponible). La procedencia de estas informaciones nos es, por el momento, desconocida aunque cabe pensar que existen a disposición de aquellos que realizan la derrama instrumentos que les ayudaron en esta tarea.

En primer lugar, la presencia -al menos en algunas de las diócesis-de una nutrida representación del clero regular y secular en el otorgamiento de las tasaciones y/o acuerdos de reparto debe tener su causa en la necesidad no sólo de llegar a un acuerdo sino de establecer valoraciones veraces -puesto que todos han de contribuir, cada uno de los cotizantes realizaría una función de control respecto a los demás ${ }^{72}-$.

Los refentes informativos más importantes fueron muy posiblemente un nutrido grupo de documentos procedentes de la administración episcopal. Los escasos escritos de uso interno de estas oficinas que se han conservado incluyen algunas relaciones con el valor de rentas beneficiales, ya porque pertenecen total o parcialmente al prelado, ya

\footnotetext{
${ }^{71}$ En este sentido habría que interpretar, quizás, el acuerdo del obispo de Mondoñedo con el monasterio de Lourenzá.

${ }^{72}$ Por ejemplo, cada arcipreste tendría especial interés en reducir la aportación de su distrito - una parte de la cual sale de sus ingresos- en detrimento de los demás, que intentarían la misma maniobra.
} 
porque están en disputa ${ }^{73}$. La información de primera mano procede, seguramente, de los datos aportados por las visitas arcedianales y episcopales, que registran escrupulosamente el número de beneficios de cada parroquia (incluidos las capellanías y hospitales), quien los sirve y a quien pertenece la colación; en estos escritos, el valor anual de los beneficios es un item incontestable y es constantemente actualizado -entre otras cosas porque un porcentaje repercute en el arcediano y en el prelado- ${ }^{74}$. En Santiago, en 1395, existe noticia precisa de la existencia de un libro do arçediano, cuya misión es organizar y registrar estos datos básicos ${ }^{75}$.

Los datos procedentes de estos tipos documentales necesitan una sistematización que implica el establecimiento del censo de contribuyentes y la tasa que corresponde a cada uno.

Dado que el impuesto no es per capita -no lo paga cada clérigo ${ }^{76}$ - sino por beneficio, cabe pensar que el censo o relación de beneficios es prácticamente estable y que únicamente se modificaría tras la erección de una nueva entidad, hecho por otra parte no muy frecuente desde mediados del siglo XIV. Esta información se encuentra ya disponible en los repartimientos realizados por diferentes motivos entre la clerecía local. Estas derramas tienen, a tenor de nuestras fuentes, dos causas fundamentales: afrontar pro-

\footnotetext{
${ }^{73}$ Aunque conservamos algunos ejemplos, conocemos su existencia, sobre todo, por su inclusión en los diferentes inventarios de los archivos episcopales GARCÍA ORO, J.;VÁZQUEZ BERTOMEU, M.; \& RODRÍGUEZ SUÁREZ, M.P., «El obispo fray Antonio de Guevara y la documentación mindoniense», Estudios Mindonienses 11 (1995): pp. 49-77; VÁZQUEZ BERTOMEU, M., «El archivo de Alonso de Fonseca III, arzobispo de Santiago", Estudios Mindonienses 17 (2001): pp. 542-573)

${ }^{74}$ Archivo Histórico Diocesano de Santiago (AHDS), Fondo General Leg. 1262, $\mathrm{n}^{\circ}$ 2, 4, 13, 25; Ibidem, Fondo de San Martín Pinario (FSMP) Leg. 59, nº 39 y CID, C., «Una visita pastoral a la diócesis auriense en 1487», Boletín de la Comisión de Monumentos de Orense 5 (1916): 187-192, 205-208, 221-224, 226-233, 261-264, 294-296, 320-326, 352-358, 373; GARCÍA ORO, J., «La vida religiosa en el valle de Oro a principios del siglo XVI», Compostellanum (1979): pp. 123-157; GARCÍA Y GARCÍA, A., «Dos visitas a Bretoña», Compostellanum 23 (1978): pp. 169-189; GONZÁLEZ LOPO, D.L. \& PRESEDO GARAZO, A., «A visita pastoral de Juan Manxón ó arcediagado de Cornado en 1519», Cuadernos de Estudios Gallegos XLV, 110 (1998): pp. 31-72.

${ }^{75}$ AHDS, FSMP Leg. 9, f1 62r-62v.

${ }^{76} \mathrm{La}$ tributación personal lleva consigo más complejos procedimientos cfr. McHARDY, A.K., Clerical Poll-Taxes of the Diocese of Lincoln, 1377-1381, Lincoln, 1992.
}

«CUADERNOS DE ESTUDIOS GALLEGOS», Tomo XLIX, Fascículo 115, Santiago 2002. 
cesos judiciales que afectan a total o parcialmente al grupo o hacer frente a los llamados "subsidios caritativos» o pedidos que se entregan al obispo. No se conservan nóminas relativas al pago de procuradores que siguen procesos, pero sí muchas referencias a este tipo de repartos. Los pedidos episcopales son objeto de un buen número de noticias documentales ya sea porque el sínodo aprueba su concesión -generalmente negociada-, porque se ejecutan impagos o porque se deja constancia escrita de disconformidades con la tasa o la decisión prelacial. Existen, incluso, dos noticias muy precisas sobre este tema. En Santiago, existe -al menos desde 1435-un padron rotulo en el que constan todos los beneficios con su cuota, que debe ser expuesto para que cada uno sepa cual es la cantidad máxima que debe pagar $^{77}$. Conservamos un documento de este tipo otorgado por el clero de Ourense en $1425^{78}$. Ambas noticias inducen a pensar que son estos documentos de reparto del pedido episcopal el referente informativo más importante a la hora de confeccionar las relaciones del subsidio.

No obstante, el padrón-rótulo compostelano y el repartimiento orensano, son tipológicamente documentos que ilustran dos momentos diferentes. Mientras que el primero parece establecer la tasa máxima a cotizar por cada contribuyente (una tasación propiamente dicha), el segundo contiene la relación efectiva de lo que cada uno paga en un momento dado (un padrón de tributación) ${ }^{79}$. Media entre ambos una serie de procesos de cálculo que suponen una adaptación de la base imponible a la cantidad global a recaudar. Las diligencias que conducen de uno a otro son las siguientes: establecido el censo y aclarados los ingresos anuales de cada unidad de tributación, se calcula cuál es la tasa máxima a pagar que permanecería más o menos estable al menos durante algún tiempo ${ }^{80}$ y, de este modo, se obtiene la tasación. A la hora de llevar a cabo la recaudación -si se utiliza una tasación anterior- debe realizarse un nuevo cóm-

${ }^{77}$ Sínod. 1435, c. 4 (ed. en GARCÍA Y GARCÍA, Synodicon).

${ }^{78}$ VAQUERO DÍAZ, Celanova, doc. $\mathrm{n}^{\circ} 265$.

${ }^{79}$ Sobre los tipos documentales, si bien aplicados al ámbito local ver ROMERO MARTÍNEZ, A., Los papeles del fisco. Estudio diplomático de la documentación fiscal castellana bajomedieval, Granada, 1998; pp. 152-184.

${ }^{80} \mathrm{O}$, como ocurre durante un largo período durante el reinado de los RRCC y en adelante, cuando la cantidad solicitada por la Corona sea la misma, y no se producen grandes cambios en la geografía diocesana. 
puto para ajustar la cantidad global de pago $-\mathrm{y}$, por lo tanto, cada aportación individual-al total exigido, que no necesariamente es el mismo; se realizará entonces lo que se denomina un repartimiento o moderación.

A tenor de nuestras informaciones, este esquema sólo puede aplicarse claramente a partir de la intervención del protonotario Altamirano cuyas tasaciones -según él mismo dispone y la documentación atestigua- son actualizadas y tomadas como referencia en posteriores recaudaciones ${ }^{81}$. No es posible, por el momento, establecer si este era el procedimiento seguido con anterioridad, aunque cabe pensar que al menos en los primeros tiempos -cuando la elaboración de la tasación estaba en manos de los agentes pontificios- fue asi; quizás que incluso que durante largo tiempo -sobre todo mientras el gravamen era decimal- la tasación permaneció durante largos períodos como instrumento de referencia, pues tendría la ventaja de la virtual congelación de la tasa al no actualizarse los valores.

No ha sido posible establecer en ninguno de los casos cómo se llevan a cabo los distintos cálculos y operaciones matemáticas que necesitan para concretar el canon que cada beneficio debe pagar. Es necesario para obtener el valor unitario, computar en moneda las distintas rentas percibidas en especie; sobre esta cantidad calcular el valor de tasación (inicialmente un $10 \%$ pero después entre un 5 ó un $8 \%{ }^{82}$ ); y, cuando fuese necesario, actualizar todos estos valores.

El documento conservado procedente de Mondoñedo es, a este efecto, singular pues los datos que nos proporciona se refieren al valor íntegro de los beneficios pero también a su tasa, lo que nos permite conocer con exactitud -al menos para este caso- que el cálculo aplicado es la decimación ${ }^{83}$.

\section{Características documentales}

Diplomáticamente, las tasaciones y repartimientos conservados presentan características muy semejantes, puesto que en realidad lo único que las diferencia es su valor temporal -cabe pensar incluso que los

${ }^{81}$ ACS, Actas Capitulares III, $\mathrm{f}^{\mathrm{o}}$ 230r; Actas Capitulares V, $\mathrm{f}^{\mathrm{o}}$ 57r. Del documento mindoniense se elaboró un segundo ejemplar -posiblemente para ser usado en una recaudación.

${ }^{82}$ LADERO QUESADA, El siglo $X V$; pp. 193-194.

${ }^{83}$ CAL PARDO, Colección diplomática; doc. $\mathrm{n}^{\circ} 206$. 
repartimientos fuesen usados posteriormente como instrumentos de referencia. Salvo las elaboradas por orden del protonotario Altamirano en Santiago $^{84}$ (que introducen directamente la tasación), presentan forma de testimonio notarial de un acuerdo de reparto. En un breve protocolo inicial exponen las razones y contenido del documento. Sigue a continuación la relación de contribuyentes, cada nombre seguido de una cantidad, con la expresión de la moneda.

Es un escrito concebido con un caracter eminentemente utilitario que se refleja en la disposición de la página y en la ordenación del texto. Los items se agrupan por grupos o entidades similares (monasterios, dignidades, arciprestadgos de cada arcedianato, beneficios de cada arciprestadgo,...) en dos columnas -una para los contribuyentes, otra para la cantidad que les corresponde-.

Las tasaciones de Altamirano -Mondoñedo y Santiago- han sido elaboradas con vocación de permanencia y uso futuro, están firmadas por notario y separan de modo claro los distritos grupos de tributacion, presentan una escritura más esmerada -que en el caso de Santiago podría calificarse como ornamental dado el uso de diferentes tintas y los modulos de los diferentes títulos. Toman forma de libro - de pergamino en Santiago, de papel en Mondoñedo- y están autorizadas en pública forma.

Los repartimientos de Ourense, a pesar de compartir la intención de claridad expositiva en el ordenamiento de la página, se nos presentan como escritos simples, carentes de suscripción notarial -lo que denotaría su uso como instrumento preparatorio, de validez temporal o de caracter interno. Existen noticias, no obstante de la existencia en diferentes diócesis de Libros de subsidio, que posiblemente contendrían las tasaciones, que sirvieron como referencia de estos repartimientos ${ }^{85}$.

\section{La tradición documental}

El único original auténtico es el documento elaborado por orden de Pedro de Altamirano en Mondoñedo - del que se conserva, también una

\footnotetext{
${ }^{84}$ Sus características pormenorizadas en VÁZQUEZ BERTOMEU, «La Iglesia de Santiago».

${ }^{85}$ Sin. Mindon. 1350 (ed. en GARCÍA Y GARCÍA, Synodicon, ); DURO PEÑA, Catálogo; doc. $\mathrm{n}^{\circ}$ 881; ACS, Actas Capitulares II, f $\mathrm{f}^{\circ}$ 23r-23v.
}

«CUADERNOS DE ESTUDIOS GALLEGOS», Tomo XLIX, Fascículo 115, Santiago 2002. 
copia $^{86}$. El de Santiago es una copia autorizada elaborada a petición del cabildo, a causa del deficiente estado de conservación del original de Altamirano, y se optó por pasarlo a pergamino en busca de una mayor perdurabilidad del documento. Los repartimientos de Ourense son documentos simples, quizás no copias sino originales no autorizados por notario -lo que denotaría un fuerte caracter temporal, interno y utilitario.

\section{CONCLUSIONES}

Las tasaciones aqui descritas - tanto las hoy conservadas como aquellas conocidas sólo a través de los repartimientos- estuvieron en vigor durante un largo período, puesto que fueron la referencia inexcusable de las recaudaciones posteriores, cuya guía fundamental fueron.

La veracidad de los datos que aportan es algo que, por el momento, es dificil de establecer. Cabe pensar, no obstante, que las quejas y la revisión que sufrieron las realizadas por Altamirano son un síntoma de que se revisó el padrón de contribuyentes en profundidad, buscando este personaje una optimización de la recaudación a través de una nueva tasación basada quizás en criterios más objetivos que los hasta entonces utilizados.

La utilidad de estos documentos como fuente histórica es innegable puesto que nos proporcionan datos objetivos no sólo sobre la composición beneficial de cada diócesis, sino elementos que permiten cuantificar los ingresos de esos beneficios y del conjunto diocesano, percibir las diferencias locales, valorar las cuantías -si quiera relativas- de los beneficios, a pesar de la existencia de posibles ocultaciones.

Se trata, al menos para el caso gallego, de los primeros documentos de caracter estadístico de los que disponemos y constituyen el inicio de una serie documental que bajo el nombre «subsidio y décima» o «subsidio y excusado» se mantiene en los archivos catedralicios durante toda la Edad Moderna lo que permitiría -de desearlo- llevar a cabo estudios comparativos durante un largo período.

${ }^{86}$ CAL PARDO, Colección diplomática; doc. no 206.

«CUADERNOS DE ESTUDIOS GALLEGOS», Tomo XLIX, Fascículo 115, Santiago 2002. 